\title{
Deep Brain Stimulation for Treatment-Resistant Depression: Review of the Literature
}

\author{
Angelo Lavano*, Attilio Della Torre, Giorgio Volpentesta, Giusy Guzzi, Marisa De Rose and Mary Romano
}

Department of Neurosurgery, University "Magna Graecia” of Catanzaro, Italy

\begin{abstract}
Chronic Major depression is one of the most debilitating psychiatric disorders ; $8-13 \%$ of patients are treatment resistant. DBS has been applied to the following targets: Subcallosal cingulate gyrus (Brodmann 25a), Ventral Capsule and Ventral Striatum (VC/VS), Nucleus Accumbens (NA), Inferior thalamic Peduncle (ITP) Rostral Cingulate Cortex. In the contrary to neurological diseases, for major depression there is not a single pathological target structure; several brain structures presumably play different roles in the development as well as in the maintenance of symptoms; some targets are in close anatomical or functional relationship (neural networks) and an overlap of effect is plausible; different target might manipulate the pathological network at different nodes. This overview summarizes research on the mechanisms of brain networks with respect to psychiatric diseases and highlights the role of the reward system in DBS for patients with treatment-resistant depression.
\end{abstract}

Keywords: Deep brain stimulation; Major depression; ventral capsule; ventral striatum; Brodmann area 25; Subgenual cingulate; Nucleus accumbens

Abbreviations: MAO: Monoamine Oxidase; TCA: Tricyclic Antidepressants; MD: Major Depression; DBS: Deep Brain Stimulation; OCD: Obsessive-Compulsive Disorder; TRD: Treatment-Resistant Depression; SCG: Subcallosal Cingulate Gyrus; VC/VS: Ventral Capsule and Ventral Striatum; NAcc: Nucleus Accumbens; ITP: Inferior Thalamic Peduncle; MFB: Medial Forebrain Bundle; slMFB: supero-lateral branch of the Medial Forebrain Bundle; HAMD-17: 17Item Hamilton Depression Rating Scale; HDRS: Hamilton Depression Rating Scale; MADRS: Montgomery-Asberg Depression Rating Scale

\section{Introduction}

Psychosurgery was first introduced in 1930s by Moniz with the prefrontal leucotomy, a surgical method that disrupted afferent/efferent pathways of the frontal lobe and this method was further developed in the transorbital frontal lobotomy by Freeman. Operation was crude, associated with high mortality and led to unacceptable adverse effects. With discovery of psychotropic drugs (Lithium, Chlorpromazine, MAO e TCAs) in 1950s and their broad application, interest for surgery declined rapidly. Improvement in knowledge of "neurophysiology of emotion" and development of stereotactic methodology allowed to identify new targets for psychosurgery and to reach those targets precisely with minimal lesions and minimal side effects. Several ablative techniques were used for treatment of Major Depression (MD) such as anterior cingulotomy, anterior capsulotomy, subcaudate tractotomy and limbic leucotomy $[1,2]$.

Chronic Deep Brain Stimulation (DBS) has been introduced in neurosurgical practice by Benabid for treatment of movement disorders; observation of induced psychiatric side effects in patients with DBS for movement disorders gave impulse to try DBS also for psychiatric illness. Functional imaging has also played significant role in the diffusion of DBS. Another incentive was the fact that effective but irreversible ablative interventions could be emulated using DBS with a focused, fully reversible and treatable technique [3]. In 1999 there was the first report of use of DBS for a psychiatric disorder (anterior capsule DBS for OCD) [4].

$\mathrm{MD}$ is a common and heterogeneous psychiatric disorder affecting approximately $1.5 \%$ of the general population at any one time and is a significant source of worldwide disability. It is defined as a state of extreme sadness or melancholia that affects person's activities in daily life as well as social functioning. Currently, antidepressants and/or psychotherapy are the mainstay of treatment, along with electroconvulsive therapy, which is reserved for treatment-resistant individuals. In fact $8-13 \%$ of patients becomes refractory to these treatments at long-term follow-up (treatment-resistant depression or TRD) [5]. Lately DBS has emerged as potential treatment for unremitting treatment-resistant depression $[1,6]$.

Brain target selection for DBS in TRD has been guided tractography of older ablative techniques and by neuroimaging studies identifying neuroanatomical structures within putatively dysfunctional neural circuits modulating different aspects of MD via connections to limbic, cortical and subcortical areas [7]. In the contrary to neurological diseases, there is not a single pathological structure in psychiatric illness; several brain structures presumably play different roles in the development as well as in the maintenance of symptoms, some targets are in close anatomical or functional relationship (neural networks) and an overlap of effect is plausible. At last different target might manipulate the pathological network at different nodes. The primary purpose of this article is to conduct a review concerning DBS in treatment of TRD with particular attention to the used targets and their clinical results.

\section{Depression Neuroanatomy}

Depression is not the result of dysfunction in a single brain region or of a single neurotransmitter system. The symptoms of depression are not simply the result of one or more of these pathways not functioning appropriately, but also a failure of the other components of the system

*Corresponding author: Angelo Lavano, Department of Neurosurgery, University "Magna Graecia" of Catanzaro, Italy, Tel: +39 0961369 4079; E-mail: lavano@unicz.it

Received May 07, 2015; Accepted May 26, 2015; Published June 03, 2015

Citation: Lavano A, Della Torre A, Volpentesta G, Guzzi G, De Rose M, et al. (2015) Deep Brain Stimulation for Treatment-Resistant Depression: Review of the Literature. Brain Disord Ther 4:168. doi:10.4172/2168-975X.1000168

Copyright: ( 2015 Alonso F, et al. This is an open-access article distributed under the terms of the Creative Commons Attribution License, which permits unrestricted use, distribution, and reproduction in any medium, provided the original author and source are credited.t 
to maintain homeostasis in times of increased stress to the organism. Neurobiological correlates of depressive illness can be grouped into the following three main components: cortical, subcortical, and limbic

The cortical component appears to give rise to the psychomotor and cognitive aspects of depressive symptoms and consists of the prefrontal cortex, the dorsal portion of the anterior cingulate gyrus, and areas of the premotor cortex. This cortical component has access to the striatum and then creates a feedback loop via the thalamus.

The subcortical component involves the affective experiencing of depressive symptoms, including anhedonia and sadness. This aspect of the neural circuit includes, among others, the subgenual anterior cingulate (Brodmann's area 25), the orbitofrontal cortex, and limbic structures in the brain involved with negative emotions, including the nucleus accumbens and amygdala. This component also interacts with the striatum and subsequently the thalamus to create a loop.

The modulatory component seems to regulate the cortical and subcortical circuits and includes the critical neuroendocrine aspects of depressive symptoms. This "modulating pathway" involves the amygdala, pregenual anterior cingulate cortex, and the hypothalamicpituitary-adrenal axis. It is hypothesized that it mediates the cortical and limbic circuits via inhibitory projections to these circuits $[7,8]$.

\section{Review of the Literature}

In literature DBS for treatment of TRD has been applied to the following targets: Subcallosal cingulate gyrus (SCG/Brodmann 25a), Ventral Capsule and Ventral Striatum (VC/VS), Nucleus Accumbens (NAcc), Inferior Thalamic Peduncle (ITP), Lateral Habenula and Medial Forebrain Bundle (MFB) although Rostral Cingulate Cortex (Brodmann 24a) is also potentially efficacious DBS targets.

\section{DBS of Subcallosal cingulate gyrus (SCG / Brodmann 25a)}

The subcallosal cingulate gyrus (area Cg25) has critical projections to and from ventral striatum, NAcc and limbic cortical loop confirmed by diffusion tractography in humans. This area is involved in cognitive, visceromotor and vegetative physiology.

Based on a preliminary report of Mayberg of 6 patients implanted bilaterally in area Cg25 [9], Lozano et al. enrolled 14 new patients for a total of 20 patients. The electrodes were implanted in the white matter of the SCG with 3-6 V, 90 microsec, $130 \mathrm{~Hz}$ stimulation parameters and contact monopolar.

The authors studied the percentage of patients who achieved a response $(50 \%$ or greater reduction in the HAMD-17) or remission (score of 7 or less in the HAMD-17) after DBS.

The mean total HAMD-17 score was significantly improved at all time points examined 1 months or longer after DBS at baseline. Concerning early but transitory benefits $40 \%$ of patients were responders after 1 week of stimulation and one patient was in remission: these results were due to the micro-lesion effect of electrode. Authors observed a progressive improvement with chronic DBS: at one month after surgery, $35 \%$ of patients met criteria for response with $10 \%$ of patients in remission; at six months after surgery, $60 \%$ of patients were responders and $35 \%$ met criteria for remission; these benefits were largely maintained at 12 months.

The number of serious adverse effects was small with no patient experiencing permanent deficits. DBS of SCG was also associated with specific changes in the metabolic activity localized to cortical and limbic circuits implicated in the pathogenesis of depression. PET studies showed a decrease in limbic - striatal cerebral blood flow and increase in dorsal cortical after stimulation of area Cg25. At baseline FDG-PET showed elevated Cg25 metabolism (seen in responders and non-responders) and decreased PF9/46 metabolism; later FDGPET repeated at 3 and 6 months after DBS showed a decreased Cg25 metabolism, increased PF9/46 metabolism (only responders), decreased Hypothalamus, Anterior Insula, and PF10 metabolism (only responders) [10].

Kennedy et al. successively published the data about the follow-up of these 20 patients after 3 to 6 years. The average response rates 1,2 , and 3 years after DBS implantation were $62.5 \%, 46.2 \%$, and $75 \%$, respectively. At the last follow-up visit (range $=3-6$ years), the average response rate was $64.3 \%$. Functional impairment in the areas of physical health and social functioning progressively improved up to the last follow-up visit. No significant adverse events were reported during this follow-up, although two patients died by suicide during depressive relapses [11]

Holtzheimer et al. assessed the efficacy and safety of SCG DBS in patients with TRD with both major depressive disorder (ten patients) that bipolar II disorder (seven patients). Stimulation parameters were frequency $130 \mathrm{~Hz}$, amplitude $6.0 \mathrm{~V}$, pulse width $91 \mathrm{microsec}$., contact monopolar. Patients received single-blind sham stimulation for 4 weeks followed by active stimulation for 24 weeks and then entered a singleblind discontinuation phase. Patients were evaluated for up to 2 years after the onset of active stimulation. Significant decrease in depression and increase in function were associated with chronic stimulation. Remission and response were seen in 3 patients (18\%) and 7 (41\%) after 24 weeks $(\mathrm{n}=17), 5(36 \%)$ and $5(36 \%)$ after 1 year $(\mathrm{n}=14)$, and $7(58 \%)$ and $11(92 \%)$ after 2 years $(n=12)$ of active stimulation. No patient achieving remission experienced a spontaneous relapse. Efficacy was similar for patients with major depressive disorder and those with bipolar disorder. Chronic DBS was safe and well tolerated, and no hypomanic or manic episodes occurred. A modest sham stimulation effect was found, likely due to a decrease in depression after the surgical intervention but prior to entering the sham phase [12].

Puigdemont et al. published a study aimed to confirm the efficacy and measure the impact of discontinuation of DBS. It represents the first 6-month double-blind, randomized, sham-controlled crossover study on five implanted patients with previous severe TRD who experienced full remission after chronic stimulation. For each the following stimulation parameters were maintained: frequency $130-135 \mathrm{~Hz}$, amplitude 3,5-5 V, pulse width 120-240 microsec., contact monopolar. After more than 3 months of stable remission, patients were randomly assigned to 2 treatment arms: the ON-OFF arm, which involved active electrode stimulation for 3 months followed by sham stimulation for 3 months, and the OFF-ON arm, which involved sham stimulation for 3 months followed by active stimulation for 3 months. The primary outcome measure was the difference in the 17-item Hamilton Rating Scale for Depression (HAMD-17) total score between sham and active stimulation. At the end of active stimulation, depression was remitted in 4 of 5 patients and none of them had experienced a relapse, whereas at the end of sham stimulation, 2 patients remained in remission, 2 relapsed and 1 showed a progressive worsening without reaching relapse criteria $[13,14]$

\section{DBS of Ventral Capsule/Ventral Striatum (VC/VS)}

Malone et al. published 17 patients with $\mathrm{MD}$, including a patient with bipolar disorder, received open-label DBS at three collaborating clinical centers $[15,16]$. Electrodes were implanted bilaterally in the VC/ VS region (ventral anterior limb of the internal capsule and adjacent 
ventral striatum). Stimulation parameters used were maintained: frequency $127 \mathrm{~Hz}$, amplitude $6.7 \mathrm{~V}$, pulse width 113 microsec.,contact monopolar. Significant improvements in depressive symptoms were observed. Mean \% change in MADRS and in HDRS scores was significant (55\% for MADRS and 57\% for HRDS) with response rates of $53 \%$ at 12 months and $71 \%$ at the last follow-up (14-67 months with average of 37.4 months) $[15,16]$.

\section{DBS of Nucleus Accumbens (NAcc)}

Schlaepfer et al. reported three patients with TRD implanted with bilateral DBS electrodes in the NAcc in which stimulation parameters (frequency $145 \mathrm{~Hz}$, amplitude $4.0 \mathrm{~V}$, pulse width 90 microsec., contact monopolar) were modified in a double-blind manner. Clinical ratings improved in all three patients (mean \% change of $42 \%$ in HDRS and $31 \%$ in MADRS) in on-stimulation and worsened in all three patients in off-stimulation. Effects were observable immediately and no side effects occurred. FDG-PET study showed increase in metabolism after stimulation in NAcc, amygdala, dorsolateral and dorsomedial prefrontal cortex, decrease in metabolism in medial prefrontal cortex and caudate $[17,18]$.

Bewernick et al published long-term outcomes of a larger series of 11 patients with \% change of 31\% in HDRS and 33\% in MADRS [19]. In this series stimulation parameters were frequency $130 \mathrm{~Hz}$, amplitude 5.0-8.0 V, pulse width 90 microsec, contact monopolar.

\section{DBS of Inferior thalamic peduncle (ITP)}

Jimenez et al. reported one patient with TRD and ObsessiveCompulsive Disorder (OCD) treated with bilateral DBS of ITP. Inferior thalamic peduncle is a bundle of fibers connecting the orbito-frontal cortex with the non-specific thalamic system in a small area behind the fornix and anterior to the polar reticular thalamic nucleus; both ITP and orbito-frontal cortex have proven to be hyperactive in depression, phenomenon that reverses with effective pharmacological treatment.

After 8 months of stimulation (frequency $130 \mathrm{~Hz}$, amplitude 3.0$5.0 \mathrm{~V}$, pulse width $450 \mathrm{microsec}$, contact bipolar) the patient entered in a double-blind protocol with stimulation off. During the stimulationON there was a global improvement in HDRS, function and neuropsychological scores, while during stimulation-OFF spontaneous fluctuations of symptoms were reflected by HDRS without return to pre-implanted scores [20].

\section{DBS of Lateral Habenula}

Sartorius et al., based on their hypothesis of an overactivation of the habenula in human major depressive episodes, reported one case of DBS of the Lateral Habenula with an amplitude of $10.5 \mathrm{~V}$. The procedure resulted in a sustained full remission of depressive symptoms after 60 weeks of stimulation [21].

\section{DBS of Medial Forebrain Bundle (MFB)}

Schlaepfer et al. performed DBS of the supero-lateral branch of the Medial Forebrain Bundle (slMFB) in seven patients with highly refractory depression with the following parameters of stimulation: frequency $130 \mathrm{~Hz}$, amplitude 2.4-3.5 mA left and 2.3-3.1 mA right, pulse width 60 microsec, contact bipolar. Six patients had a rapid response and mean MADRS of the whole series was reduced by $50 \%$ at day 7 after onset of stimulation. At last observation (12-33 weeks), six patients were responders; among them, four were classified as remitters. Social functioning (Global Assessment of Functioning) improved in the sample as a whole from serious to mild impairment [22].

\section{Discussion}

DBS is an unique, very promising and "ultima ratio" therapy for the treatment of therapy-resistant psychiatric patients. Current neurocircuitry models of depression are largely based on neuroimaging findings in depressed vs normal subjects $[23,24]$. These findings, acquired with $\mathrm{fRMI}$ and PET, include hypermetabolism of the subgenual cingulate cortex in the depressed vs remitted state, hyperreactivity of the amygdala [25] to negative stimuli and hypometabolism of the dorsolateral prefrontal cortex and striatum $[3,26,27]$. DBS results in modulation and regulation of the abnormal brain networks and it is believed that high-frequency stimulation has inhibitory effect while a low-frequency stimulation has excitatory effect [28]. In DBS multiple targets along nodes in a circuit may lead to treatment but with variable effect. It is probably due not only to illness heterogeneity, individual neuroanatomical variability and variable time courses of the therapeutic effects of stimulation but also to psychosocial support, personality and temperament $[6,29]$. For this reason the combination of functional neuroimaging with specific biomarkers could be helpful in identifying biologically distinct phenotypes within the TRD spectrum $[17,30]$. Besides DBS may become a therapeutic alternative for the long-term management of severe and chronic TRD as it does not seem to produce cognitive side effects $[15,16]$. The SCG has been demonstrated to be an important node in the mood regulation circuitry [7,9,12,14,15,31-34]. DBS of SCG carries the benefit of treating both unipolar and bipolar depression [12] while appearing not to have the risk of mania seen with other depression targets [34].

The Mayberg group demonstrated an initial response rate of $41 \%$ $66 \%$ at $24-26$ weeks, increased to $64 \%-92 \%$ at two-to-six years. DBS applied to the NAcc demonstrated response and remission rates at 12 months of $50 \%$ and $45 \%$ respectively and at 24 months of $30 \%$ and $9 \%$ respectively $[19,35]$. DBS applied to VC/VS demonstrated at 6 months a response rate of $40 \%$ and a remission rate of $20 \%$ and $71 \%$ and $35 \%$ at 14-67 months follow-up $[15,16]$. DBS applied to MFB seems to be a very promising neuromodulation procedure for its robust antidepressant effect that reaches a full remission of the symptoms at short-term follow-up. Its efficacy may be due to the close functional and anatomical relationship with NAcc [36]. In all examined studies it is observed the use of high amplitudes of stimulation; the need of considerable amount of electrical current delivered raises the problem of battery exhaustion and the opportunity to use rechargeable devices.

As a result, DBS is to be possibly offered to the most refractory cases of MD, trying to limit the enormous costs associated with management of chronic TRD [37,38]. At first sight, there is no need for specific ethical criteria for DBS in psychiatric disorders, but the same criteria as for DBS in movement disorders as for any other biomedical intervention can be applied: a) DBS has to benefit the patient (principle of beneficence), b) DBS do no harm to the patient (principle of non maleficence) and c) DBS reflects individual patient preferences (principle of respect of autonomy) (Table 1).

\section{Conclusion}

DBS for TRD is a promising therapy. The two most investigated targets found in the literature are SCG and VC/VS but several other targets are being used. Some studies suggest that DBS applied to the SCG is potentially efficacious and acceptable for treating chronic and severe TRD both in the short and in the medium to long-term but larger and more representative series should be included.

However until today the most appropriate targets, the optimal 
Citation: Lavano A, Della Torre A, Volpentesta G, Guzzi G, DE Rose M, et al. (2015) Deep Brain Stimulation for Treatment-Resistant Depression: Review of the Literature. Brain Disord Ther 4:168. doi:10.4172/2168-975X.1000168

Page 4 of 5

\begin{tabular}{|c|c|c|c|c|c|}
\hline Target & Authors/ Year & N. of patients & Study design & $\begin{array}{l}\text { Mean parameters of } \\
\text { stimulation }\end{array}$ & $\begin{array}{l}12 \text { months \% } \\
\text { responders }\end{array}$ \\
\hline \multirow{3}{*}{$\begin{array}{c}\text { Subcallosal cingulate } \\
\text { gyrus }\end{array}$} & [9-11] & 20 & $\begin{array}{l}\text { Uncontrolled study; } \\
\text { multisite study. } \\
\text { Systematic parameter } \\
\text { search, blinding phase, } \\
\text { up to } 6 \text { years follow-up }\end{array}$ & $\begin{array}{c}\text { Mean parameters } 124.7 \mathrm{~Hz}, \\
70.6 \mu \mathrm{s}, \\
4.3 \mathrm{~V} \\
\text { bilateral, monopolar } \\
\text { stimulation }\end{array}$ & $55 \%$ \\
\hline & [13] & 8 & $\begin{array}{l}\text { Uncontrolled study; } \\
12 \text { months observation }\end{array}$ & $\begin{array}{l}4.2 \mathrm{~V} \\
135 \mathrm{~Hz} \\
90 \mu \mathrm{s}, \\
\text { bipolar } \\
\text { stimulation }\end{array}$ & $62.5 \%$ \\
\hline & [12] & $\begin{array}{l}10 \text { MDD; } 7 \\
\text { bipolar }\end{array}$ & $\begin{array}{l}\text { Single blind sham } \\
\text { phase }(4 \text { weeks, } \\
\qquad \mathrm{n}=3)\end{array}$ & $\begin{array}{l}130 \mathrm{~Hz} \\
90 \mu \mathrm{s} \\
5-8 \mathrm{~mA}\end{array}$ & $43 \%$ \\
\hline VC/vs & {$[15,16]$} & 17 & Up to 5.5 years & $\begin{array}{l}6.7 \mathrm{~V} \\
113.0 \mu \mathrm{s} \\
127.0 \mathrm{~Hz}\end{array}$ & $53 \%$ \\
\hline \multirow[b]{2}{*}{ NAcc } & [17] & 3 & Double-blind phase & $\begin{array}{c}4.0 \mathrm{~V}, \\
90 \mu \mathrm{s}, \\
145 \mathrm{~Hz} \\
\text { monopolar stimulation }\end{array}$ & $42 \%$ \\
\hline & [19] & 11 & $\begin{array}{c}\text { Up to } 4 \text { years observation, } \\
\text { blinding phase, systematic } \\
\text { parameter search }\end{array}$ & $\begin{array}{c}5-8 \mathrm{~V}, \\
90 \mu \mathrm{s}, \\
130 \mathrm{~Hz} \\
\text { monopolar stimulation }\end{array}$ & $45 \%$ \\
\hline ITP & [20] & 1 & $\begin{array}{l}\text { Case report; } 24 \text { months } \\
\text { follow-up, } 2 \text { months } \\
\text { blinding phase; Comorbid; } \\
\text { Personality disorder } \\
\text { and bulimia nervosa }\end{array}$ & $\begin{array}{c}3.0-5.0 \mathrm{~V} \\
130 \mathrm{~Hz} \\
450 \mu \mathrm{s}\end{array}$ & $\begin{array}{c}\text { Remission of } \\
\text { depression, } \\
\begin{array}{c}\text { Relapse during blinding } \\
\text { off phase }\end{array}\end{array}$ \\
\hline Lateral Habenula & [21] & 1 & $\begin{array}{l}\text { Case report; } \\
60 \text { weeks, no } \\
\text { blinding phase }\end{array}$ & $\begin{array}{l}5 \text { to } 10.5 \mathrm{~V}, 165 \mathrm{~Hz}, \\
60 \mu \text { s pulse width } \\
\text { No acute effects, } \\
\text { Stimulation I ( } 5 \mathrm{~V} \text { ): } \\
\text { Relapse: Stimulation II } \\
\text { (increased to } 10.5): \\
\text { full and stable remission } \\
\text { Stimulation III (after } \\
\text { relapse due to stimulation } \\
\text { stop because of bike } \\
\text { accident): }\end{array}$ & $\begin{array}{l}\text { Patient reached } \\
\text { remission } \\
\text { after } 12 \text { weeks of } \\
\text { high-voltage DBS }\end{array}$ \\
\hline sIMFB & [18] & $\begin{array}{l}6 \text { MDD; } 1 \\
\text { bipolar }\end{array}$ & Uncontrolled study & $\begin{array}{c}2-3 \mathrm{~V} \\
60 \mu \mathrm{s}, \\
130 \mathrm{~Hz} \\
\text { Bipolar stimulation }\end{array}$ & $\begin{array}{c}85 \% \text { Responders at } 3 \\
\text { months (response } \\
\text { within } \\
\text { days of stimulation) }\end{array}$ \\
\hline
\end{tabular}

Table 1: DBS Studies in Major Depression.

stimulation parameters and the long-term effects and efficacy remain uncertain. Much efforts are needed to develop more appropriate selection criteria for determining which patients would benefit from DBS, taking into account the justified political and psychiatry-critical dimensions of psycho-neurosurgical operations and to publish more randomized controlled trials of DBS in treatment resistant depression.

\section{References}

1. Larson PS (2008) Deep brain stimulation for psychiatric disorders. Neurotherapeutics 5: 50-58

2. Taghva AS, Malone DA, Rezai AR (2013) Deep brain stimulation for treatmentresistant depression. World Neurosurgery 80:S27.e17-S27.e24

3. Ressler KJ, Mayberg HS (2007) Targeting abnormal neural circuits in mood and anxiety disorders: from the laboratory to the clinic. Nat Neurosci 10: 1116-1124.

4. Nuttin BJ, Gabriels LA, Cosyns PR, Meyerson BA, Andreewitch S, et al. (2003) Long-term electrical capsular stimulation in patients with obsessive-compulsive disorder. Neurosurgery 52: 1263-1274.

5. Williams NR, Okun MS (2013) Deep brain stimulation (DBS) at the interface of neurology and psychiatry. J Clin Invest 123: 4546-4556.

6. Anderson RJ, Frye MA, Abulseoud OA, Lee KH, McGillivray JA, et al. (2012) Deep brain stimulation for treatment-resistant depression: efficacy, safety and mechanisms of action. Neurosci Biobehav Rev 36: 1920-1933.

7. Drevets WC, Ongur D, Price JL (1998) Neuroimaging abnormalities in the subgenual prefrontal cortex: implications for the pathophysiology of familial mood disorders. Mol Psychiatry 3: 220-226.

8. Morishita T, Fayad SM, Higuchi MA, Nestor KA, Foote KD (2014) Deep brain 
Citation: Lavano A, Della Torre A, Volpentesta G, Guzzi G, DE Rose M, et al. (2015) Deep Brain Stimulation for Treatment-Resistant Depression: Review of the Literature. Brain Disord Ther 4:168. doi:10.4172/2168-975X.1000168

stimulation for treatment-resistant depression: systematic review of clinical outcomes. Neurotherapeutics 11: 475-484

9. Mayberg HS, Lozano AM, Voon V, McNeely HE, Seminowicz D, et al. (2005) Deep brain stimulation for treatment-resistant depression. Neuron 45: 651-660.

10. Lozano AM, Mayberg HS, Giacobbe P, Hamani C, Craddock RC, et al. (2008) Subcallosal cingulate gyrus deep brain stimulation for treatment-resistant depression. Biol Psichiatry 64: 461-467.

11. Kennedy SH, Giacobbe P, Rizvi SJ, Placenza FM, Nishikawa Y, et al. (2011) Deep brain stimulation for treatment-resistant depression: follow-up after 3 to 6 years. Am J Psychiatry 168: 502-510.

12. Holtzheimer PE, Kelley ME, Gross RE, Filkowski MM, Garlow SJ, et al. (2012) Subcallosal cingulate deep brain stimulation for treatment-resistant unipolar and bipolar depression. Arch Gen Psychiatry 69: 150-158.

13. Puigdemont $D$, Pérez-Egea R, Portella MJ, Molet J, de Diego-Adeliño J, et al. (2011) Deep brain stimulation of the subcallosal cingulate gyrus: further evidence in treatment-resistant major depression. Int J Neuropsychopharmacol 15: $121-133$.

14. Puigdemont D, Portella M, Pérez-Egea R, Molet J, Gironell A, et al. (2015) A randomized double-blind crossover trial of deep brain stimulation of the subcallosal cingulate gyrus in patients with treatment-resistant depression: a pilot study of relapse prevention. J Psychiatry Neurosci 40: 130295.

15. Malone DA Jr, Dougherty DD, Rezai AR, Carpenter LL, Friehs GM, et al. (2009) Deep brain stimulation of the ventral capsule/ventral striatum for treatmentresistant depression. Biol Psychiatry 65: 267-275.

16. Malone DA Jr (2010) Use of deep brain stimulation in treatment-resistan depression. Cleve Clin J Med 77 Suppl 3: S77-80.

17. Schlaepfer TE, Cohen MX, Frick C, Kosel M, Brodesser D, et al. (2008) Deep brain stimulation to reward circuitry alleviates anhedonia in refractory major depression. Neuropsychopharmacology 33: 368-377.

18. Schlaepfer TE, Bewernick BH, Kayser S, Mädler B, Coenen VA (2013) Rapid effects of deep brain stimulation for treatment-resistant major depression. Biol Psychiatry 73: 1204-1212.

19. Bewernick BH, Kayser S, Sturm V, Schlaepfer TE (2012) Long-term effects of nucleus accumbens deep brain stimulation in treatment-resistant depression: evidence for sustained efficacy. Neuropsychopharmacology 37: 1975-1985.

20. Jiménez F, Velasco F, Salín-Pascual R, Velasco M, Nicolini H, et al. (2005) Neuromodulation of the inferior thalamic peduncle for major depression and obsessive compulsive disorder. Acta Neurochir Suppl 97: 393-398.

21. Sartorius A, Kiening KL, Kirsch P, von Gall CC, Haberkorn U, et al. (2010) Remission of major depression under deep brain stimulation of the lateral habenula in a therapy-refractory patient. Biol Psychiatry 67: e9-e11.

22. Coenen Va, Panksepp J, Hurwitz TA, Urbach H, Madler B (2012) Human medial forebrain bundle (MFB) and anterior thalamic radiation (ATR): imaging of two major subcortical pathways and the dynamic balance of opposite affects in understanding depression. J Neuropsychiatry Clin Neuorsci 24: 223-236.
23. Hamani C, Nóbrega JN (2010) Deep brain stimulation in clinical trials and animal models of depression. Eur J Neurosci 32: 1109-1117.

24. Price JL, Drevets WC (2010) Neurocircuitry of mood disorders Neuropsychopharmacology 35: 192-216.

25. Davidson RJ (2002) Anxiety and affective style: role of prefrontal cortex and amygdala. Biol Psychiatry 51: 68-80.

26. Miller EK, Cohen JD (2001) An integrative theory of prefrontal cortex function Annu Rev Neurosci 24: 168-202.

27. Savitz J, Drevets WC (2009) Bipolar and major depressive disorder: neuroimaging the developmental-degenerative divide. Neurosci Biobehav Rev 33: $699-771$

28. Rezai A (2012) Deep brain stimulation (DBS) for treatment-resistant depression a randomized controlled trial. 2012 ASSFN Biennal Meeting Abstracts-Oral Presentation. June 3-6 2012. San Francisco, California, USA

29. Blomstedt P, Sjöberg RL, Hansson M, Bodlund O, Hariz MI (2011) Deep brain stimulation in the treatment of depression. Acta Psychiatr Scand 123: 4-11.

30. McGrath CL, Kelley ME, Holtzheimer PE, Dunlop BW, Craighead WE, et al. (2013) Toward a neuroimaging treatment selection biomarker for major depressive disorder. JAMA Psychiatry 70: 821-829.

31. Mayberg HS (2013) Optimizing subcallosal cingulate DBS for treatment resistant depression. Society of Biological Psychiatry 68th Annual Scientific Convention, May 16-18 2013. San Francisco, California, USA.

32. Ramasubbu RA (2013) Double-blind optimization of subcallosal cingulate deep brain stimulation for treatment-resistant depression: a pilot study. Society of Biological Psychiatry 68th Annual Scientific Convention, May 16-18 2013. San Francisco, California, USA.

33. Riva-Posse P, Holtzheimer PE, Garlow SJ, Mayberg HS (2012) Practica considerations in the development and refinement of subcallosal cingulate white matter deep brain stimulation for the treatment resistant depression. World Neurosurg 80: S27.e25-e34

34. Haq IU, Foote KD, Goodman WK, Ricciuti N, Ward H, et al (2010) A case of mania following deep brain stimulation for obsessive compulsive disorder. Stereotact Funct Neurosurg 88: 322-328.

35. Bewernick BH, Hurlemann R, Matush A, Kayser S, Grubert C, et al. (2010) Nucleus accumbens deep brain stimulation decreases ratings of depression and anxiety in treatment-resistant depression. Biol Psichiatry 67: 110-116.

36. Mavridis IN (2015) Deep brain stimulation for psychiatric disorders: Are nucleus accumbens and medial forebrain bundle two branches of the same tree? Neurosci Biobehav Rev.

37. Crown WH, Finkelstein S, Berndt ER, Ling D, Poret AW, et al. (2002) The impact of treatment-resistant depression on health care utilization and costs. J Clin Psychiatry 63: 963-971.

38. Russell JM, Hawkins K, Ozminkowski RJ, Orsini L, Crown WH, et al. (2004) The cost consequences of treatment-resistant depression. J Clin Psychiatry 65: 341-347. 